УДК 656.073

\title{
ВИБІР ВИДУ ПЕРЕВЕЗЕНЬ ВАНТАЖІВ 3 ВИКОРИСТАННЯМ ПОЛОЖЕНЬ ТЕОРІЇ НЕЧІТКИХ МНОЖИН
}

\author{
Асп. О.О. Шапатіна
}

\section{ВЫБОР ВИДА ПЕРЕВОЗОК ГРУЗОВ С ИСПОЛЬЗОВАНИЕМ ПОЛОЖЕНИЙ ТЕОРИИ НЕЧЕТКИХ МНОЖЕСТВ}

\author{
Асп. О.А. Шапатина
}

CHOICE OF TYPE OF CARGO using the provisions of fuzzy sets

\section{Graduate O. Shapatina}

У статті розглянуто підхід щодо вибору виду перевезень вантажів із застосуванням положень теорії нечітких множин.

Пошук оптимального рішення виконано за допомогою програмного комплекту MathCAD, Excel при відомій иіновій матриці і коефіиієнтах приналежності, при иььому як оптимальний обирається варіант з максимальним значенням приналежності.

Ключові слова: вид перевезень вантажів, теорія нечітких множин, функиія приналежності.

В статье рассмотрен подход к выбору вида перевозок грузов с применением положений теории нечетких множеств.

Поиск оптимального решения выполнен с помощью программного комплекта MathCAD, Excel при известной иеновой матрице и коэффиииентах принадлежности, при этом в качестве оптимального избирается вариант с максимальным значением принадлежности.

Ключевые слова: вид перевозки грузов, теория нечетких множеств, функция принадлежности.

In the transition economy and industries of Ukraine to a market for rail transport is growing competition from other modes of transport, the widespread use began to take combined freight transport.

In modern conditions when choosing the type of cargo the focus provided by indicators such as the cost of transportation, speed of delivery, reliability of transport, transport safety, and even many factors 
influencing the choice of transportation. Because of such factors and multifactorial not always clear information on the service provision is necessary in the application of fuzzy sets.

Thus, in the article the approach to choosing the type of cargo transportation by using the theory of fuzzy sets.

By using the software supplied MathCAD, Excel to price matrix coefficients and accessories search is conducted and certain types of traffic has a maximum value alternative - bimodal transportation.

The technique allows you to create a database to determine freight transport technology.

Keywords: the type of cargo, the theory of fuzzy sets, function accessories.

Вступ. В умовах переходу економіки та галузей промисловості України до ринкових відносин для залізничного транспорту зростає конкуренція 3 боку інших видів транспорту, широкого застосування почали набувати комбіновані перевезення вантажів.

Постановка проблеми у загальному вигляді та їі зв'язок з важливими науковими та практичними завданнями. Обгрунтований вибір виду перевезень дозволяє значно скоротити витрати на всі складові перевезень. В умовах багатофакторності виникає потреба прийняття оптимальних рішень. Завданням прийняття рішень приділяється значна увага в наукових та прикладних дослідженнях, методах теорії вибору, експертних системах, імітаційному моделюванні, теорії ігор стосовно роботи залізниць $[1,2]$. Оскільки сучасний транспорт функціонує в умовах невизначеності оточення i перспектив розвитку, цілі управління можуть змінюватися, що викликає необхідність розробки методів нечіткої багатокритеріальної оптимізації $[3,4]$.

\begin{tabular}{cccr}
\multicolumn{1}{c}{ Аналіз } & останніх & досліджень i \\
публікацій. & Питаннями & удосконалення
\end{tabular}
змішаних, комбінованих, інтермодальних перевезень займалися такі вчені, як Бутько Т.В., Дьомін Ю.В., Кірпа Г.М., Котенко А.М., Ломотько Д.В., Мироненко В.К., Миротін Л.Б., Резер С.М., Шибаєв О.Г. та інші вітчизняні та закордонні вчені.

Відомо, що одним з головних напрямків транспортної політики Європейського Союзу в останні роки став розвиток системи комбінованих перевезень вантажів, що передбачає на основі логістичних принципів роботу суцільних транспортних ланцюгів як єдиного «перевізного конвеєра». Міжнародна практика свідчить, що більше третини всіх міжнародних вантажних перевезень здійснюється за принципом «від дверей до дверей» $[5,6]$.
Змішані перевезення являють собою один 3 напрямків технічного прогресу, що швидко розвивається на залізничному транспорті. Спостерігається тенденція до розвитку технологій змішаних перевезень, які сполучають переваги автомобільного та залізничного транспорту. Їх обсяг складає 20-25 \% загальних вантажних перевезень західноєвропейських i північноамериканських залізниць [7].

Таким чином, необхідно розробити методику, що дозволить формувати базу даних щодо визначення транспортної технології перевезення вантажів. Порівняння видів транспортних перевезень вантажів проводиться для автомобільно-залізничних, автомобільних, залізничних та бімодальних перевезень.

Визначення мети та завдання дослідження. Метою статті є обгрунтування вибору виду перевезень вантажів із застосуванням положень теорії нечітких множин.

Для досягнення мети визначені такі завдання:

- розгляд підходів щодо вибору виду перевезень вантажів;

- застосування положень теорії нечітких множин при обранні виду перевезень вантажів;

- визначення максимального значення приналежності для обрання оптимального варіанта перевезень вантажів.

Наукова новизна полягає у вирішенні науково-технічного завдання обгрунтування вибору виду перевезень вантажів із застосуванням теорії нечітких множин, що дозволить удосконалити використання транспортних засобів та забезпечить значне скорочення витрат на перевантажувальні операції.

Основна частина дослідження. В сучасних умовах при обранні виду перевезення вантажів основну увагу надають таким показникам, як вартість перевезення, швидкість доставки, надійність перевезення, схоронність вантажів та ще багатьом чинникам, що впливають на вибір виду перевезення. У зв'язку 
3 такою багатофакторністю чинників та не завжди чіткою інформацією щодо надання послуг виникає необхідність у застосуванні теорії нечітких множин.

Створення теорії нечітких множин - це спроба формалізувати людський спосіб міркувань. Розвиток обчислювальної техніки дозволяє в даний час створювати на базі теорії нечітких множин системи нечіткої логіки, які копіюють спосіб міркувань людини $[8,9]$.

Сформулюємо постановку завдання. Нехай $\epsilon$ множина із $\kappa$ альтернатив $A=\left\{a_{1}, a_{2}, \ldots, a_{i}\right\}$. Тоді для критерію $\Pi$ може бути розглянута нечітка множина

$$
\Pi=\left\{\mu_{\Pi}\left(a_{1}\right) / a_{1}, \mu_{\Pi}\left(a_{2}\right) / a_{2}, \ldots, \mu_{\Pi}\left(a_{i}\right) / a_{i}\right\},
$$

де $\mu_{\Pi}\left(a_{i}\right)[0,1]-$ оцінка альтернативи $a_{i}$ за критерієм П, який характеризує ступінь відповідності альтернативи поняттю, що визначається критерієм $\Pi$.

Якщо є $n$ критеріїв: $\Pi_{1}, \Pi_{2}, \ldots, \Pi_{n}$, то найкращою вважається альтернатива, що задовольняє і критерій $\Pi_{1}$, і $\Pi_{2}$, і $\Pi_{n}$. Тоді правило для вибору найкращої альтернативи може бути записано у вигляді перетину відповідних нечітких множин:

$$
D=\Pi_{1} \cap \Pi_{2} \cap \ldots \cap \Pi_{n} .
$$

Операції перетину нечітких множин відповідає операція min-, що виконується над їх функціями приналежності, найкращою обирається альтернатива $a^{*}$, яка має найбільше значення функції приналежності.

Розглянемо процедуру вибору варіантів видів перевезень при різній важливості вимог (критеріїв).

У випадку, якщо критерії $\Pi_{i}$ мають різну важливість, кожному з них приписується число $a_{i} \geq 0$ (чим важливіше критерій, тим більше $a_{i}$ ), і правило вибору набуває такого вигляду:

$$
\begin{gathered}
D=\Pi_{1}^{a_{1}} \cap \Pi_{2}^{a_{2}} \cap \ldots \cap \Pi_{n}^{a_{n}}, \\
a_{i} \geq 0, i=1 \ldots n, \frac{1}{n} \sum_{i=1}^{n} a_{i}=1 .
\end{gathered}
$$

Коефіцієнти відносної важливості визначаються на основі процедури парного порівняння критеріїв. Спочатку формується матриця $A$, елементи якої задовольняють такі умови: $m_{i j}=1 ; m_{i j}=1 / m_{i j}$.
Після чого визначається $w$ - власний вектор матриці $A$, який відповідає максимальному власному значенню $z_{\max }$. Шукані значення коефіцієнтів $a_{i}$ отримують множенням елементів $w$ на $n$ для виконання умови

$$
a_{i} i=n w_{i} .
$$

Поставлено завдання вибору виду транспортних перевезень вантажів для таких варіантів: $a_{1}$ - автомобільно-залізничні перевезення, $a_{2}$ - автомобільні перевезення, $a_{3}-$ залізничні перевезення, $a_{4}-$ бімодальні перевезення.

Основними вимогами (критеріями) при виборі виду перевезень були обрані такі: $\Pi_{1}-$ дальність перевезення, $\Pi_{2}-$ швидкість доставки, $\Pi_{3}$ - надійність перевезення.

В результаті експертної оцінки отримали такі дані, що характеризують ступінь приналежності видів перевезень заданим вимогам:

$$
\begin{aligned}
& \Pi_{1}=\left\{0,6 / a_{1} ; 0,3 / a_{2} ; 0,7 / a_{3} ; 0,8 / a_{4}\right\}, \\
& \Pi_{2}=\left\{0,7 / a_{1} ; 0,9 / a_{2} ; 0,6 / a_{3} ; 0,3 / a_{4}\right\}, \\
& \Pi_{3}=\left\{0,5 / a_{1} ; 0,5 / a_{2} ; 0,6 / a_{3} ; 0,6 / a_{4}\right\} .
\end{aligned}
$$

Критерії мають різну важливість, результати їх попарного порівняння подані матрицею $A$. Використовуючи засоби MathCAD, знайдемо власне значення цієї матриці (функція eigenvals $(A)$ ) і власний вектор, відповідний максимальному власному значенню (функція eigenvec $(A, z))$ [10]. 
Матриця важливості має вигляд

$$
A:=\left\{\begin{array}{ccc}
1 & 3 & 1 / 5 \\
1 / 3 & 1 & 1 / 7 \\
5 & 7 & 1
\end{array}\right\}
$$

Власне значення матриці за допомогою функціï eigenvals $(A)$ MathCAD набуває вигляду

$$
\text { eigenvals }(A)=\left\{\begin{array}{rrr} 
& 3,065 & \\
-0,032 & & +0,445 i \\
-0,032 & & -0,445 i
\end{array}\right\} \text {. }
$$

Власний вектор, що відповідає максимальному власному значенню за допомогою функції eigenvec $(A, z)$ MathCAD, має вигляд

$$
\text { eigenvec }(A, 3,065)=\left\{\begin{array}{l}
w_{1} \\
w_{2} \\
w_{3}
\end{array}\right\}=\left\{\begin{array}{l}
-0,248 \\
-0,107 \\
-0,963
\end{array}\right\} .
$$

Знаходимо коефіцієнти відносної важливості критеріїв

$$
m_{i}=m\left\{\begin{array}{l}
w_{1} \\
w_{2} \\
w_{3}
\end{array}\right\}=\left\{\begin{array}{l}
m w_{1} \\
m w_{2} \\
m w_{3}
\end{array}\right\}=\left\{\begin{array}{l}
-0,744 \\
-0,321 \\
-2,889
\end{array}\right\} .
$$

Пошук оптимального рішення проводився за допомогою програмного комплекту MathCAD, Excel при наведеній ціновій матриці і коефіцієнтах приналежності згідно з процедурою, що подана на рис. 1.

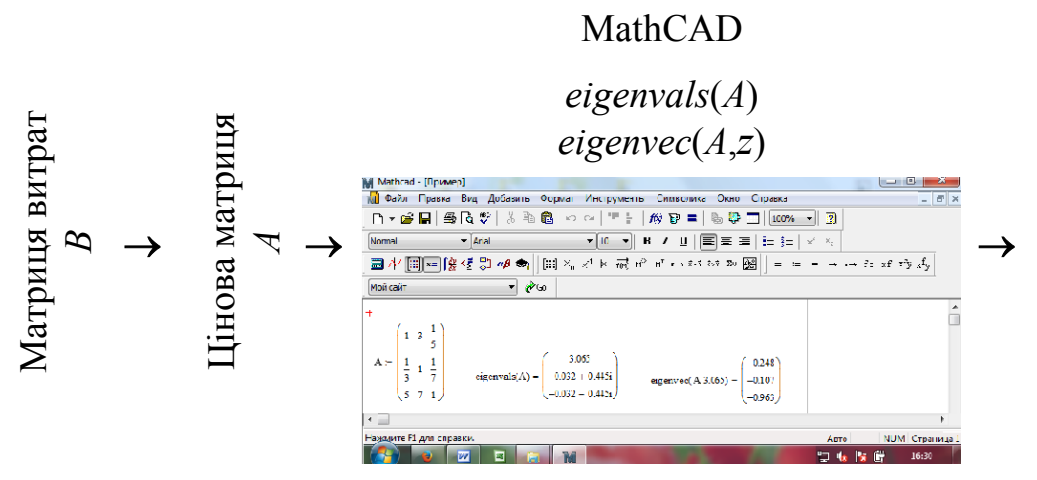

Excel

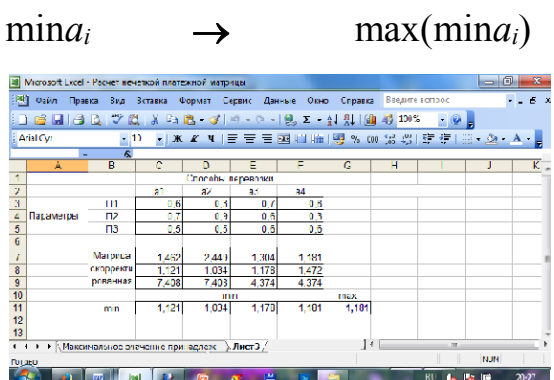

Рис. 1. Пошук оптимального рішення

В результаті розрахунків для вихідних даних отримуємо такі дані, що подані на рис. 2 у вигляді розширеного вікна.

Як видно 3 розрахунків (рис. 2), максимальне значення має альтернатива $a_{4}$ (бімодальні перевезення), другою $€ \quad a_{3}$ (залізничні перевезення), третьою $-a_{1}$ (автомобільно-залізничні перевезення), останньою - $a_{2}$ (автомобільні перевезення).
Висновки 3 дослідження і перспективи, подальший розвиток у даному напрямку:

1. За допомогою використання програмного комплекту MathCAD, Excel при ціновій матриці i коефіцієнтах приналежності проведено пошук варіантів виду перевезення i за визначеним максимальним значенням обрано альтернативу - бімодальні перевезення.

2. Запропонована методика дозволяє формувати базу даних щодо визначення транспортної технології перевезення вантажів. 


\section{Експлуатація залізниць}

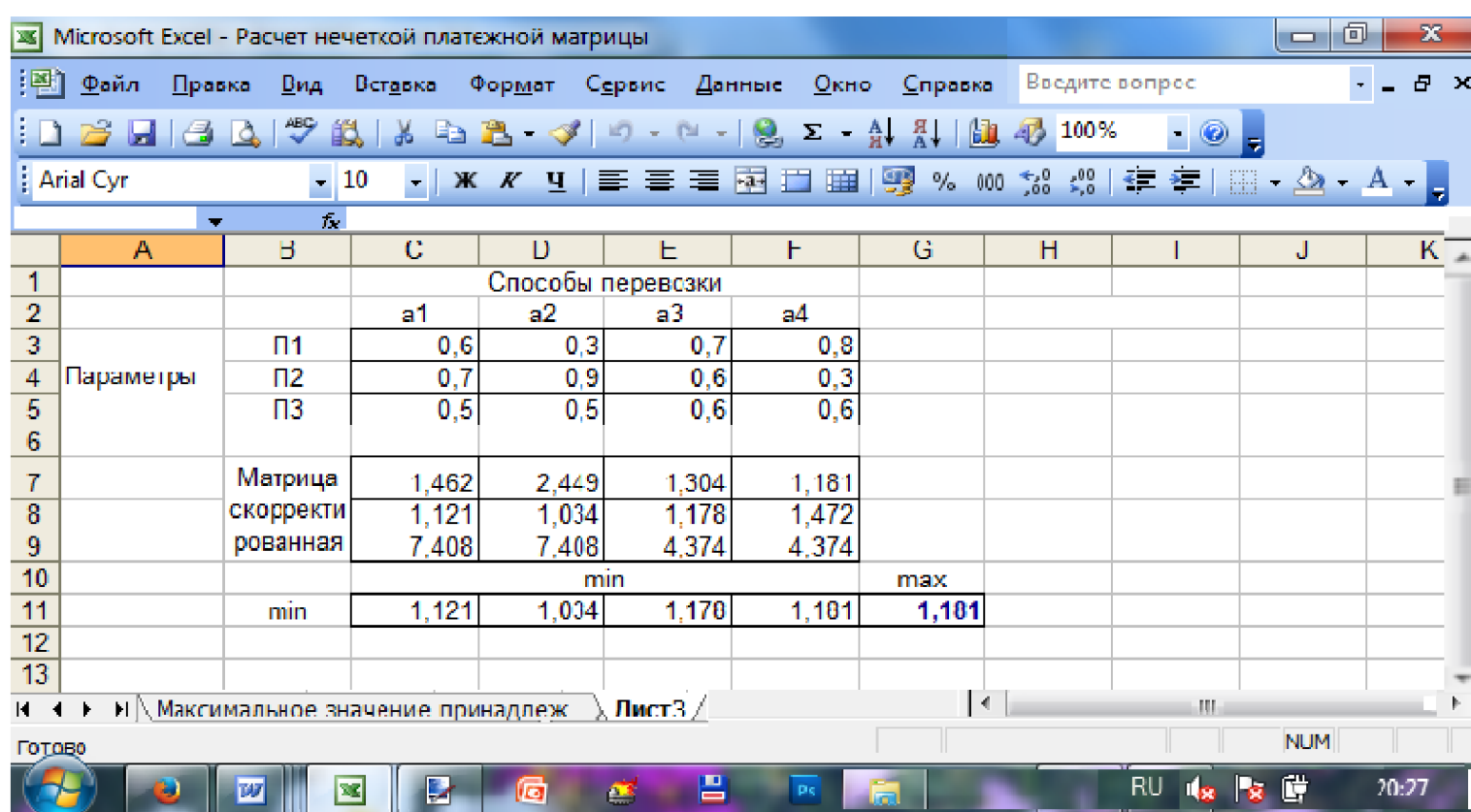

Рис. 2. Розширене вікно результатів розрахунків за допомогою програми Excel

\section{Список використаних джерел}

1. Саати, Т. Принятие решений. Метод анализа иерархий [Текст] / Т. Саати. - М.: Радио и связь, 1993. $-320 \mathrm{c}$.

2. Негойце, К. Применение теории систем к проблемам управления [Текст] / К. Негойце. - М.: Мир, 1981. - 183 с.

3. Жуковин, В.Е. Нечеткие многокритериальные модели принятия решений [Текст] / В.Е. Жуковин. - Тбилиси: Мецниереба, 1988. - 71 с.

4. Зайченко, О.Ю. Дослідження операцій [Текст]: зб. задач / О.Ю. Зайченко, Ю.П. Зайченко. К.: Слово, $2007-472$ с.

5. Проблемы и перспективы развития комбинированных (контрейлерных) перевозок в Украине [Электронный ресурс]. - Режим доступа: http://transport-journal.com/dlya-hlavnoj-stranytsyi-s-foto/ problemyi-y-perspektyvyi-razvytyya-kombynyrovannyih-kontrejlernyih-perevozok-v-ukrayne/. - Загл. с экрана.

6. Авдеев, С. Комбинированный транспорт-реальность завтрашнего дня? [Текст] / С. Авдеев // Українські залізниці. - 2014. - № 1(7). - С. 30-32.

7. Яцківський, Л.Ю. Загальний курс транспорту [Текст]: навч. посібник / Л.Ю. Яцківський, Д.В. Зеркалов. - К.: Арістей, 2007. - 544 с.

8. Кофман, А. Введение в теорию нечетких множеств [Текст] / А. Кофман. - М.: Радио и связь, 1982. $-432 \mathrm{c}$.

9. Макаров, И.М. Теория выбора и принятия решений [Текст]: учеб. пособие / И.М. Макаров, Т.М. Виноградская, А.А. Рубчинский, В.Б. Соколов. - М.: Наука, 1982. - 328 с.

10. Леоненков, А.В. Нечеткое моделирование в среде MATLAB и fuzzyTECH [Текст] / А.В. Леоненков. - СПб.: БХВ, 2005. - 736 с.

Рецензент д-р техн. наук, професор О.М. Огар

Шапатіна Ольга Олександрівна, аспірант, асистент кафедри управління вантажною і комерційною роботою, Український державний університет залізничного транспорту. Тел.: 730-10-85. E-mail: olgaparadigma@yandex.ua.

Shapatina Olga graduate, assistant chair of Manage freight and commercial work Ukrainian State University of Railway Transport. Phone: 730-10-85. E-mail: olga-paradigma@yandex.ua.

Стаття прийнята 07.09.2015 р. 